REVISTA DE ESTUDOS EM ARTES CÊNICAS

E-ISSN 2358.6958

\title{
Práticas didático-pedagógicas no ensino remoto: Desafios e possibilidades na Licenciatura em Teatro
}

Erickaline Bezerra de Lima

Erickarla Bezerra de Lima

Erickinson Bezerra de Lima

\section{Para citar este artigo:}

LIMA, Erickaline Bezerra de; LIMA, Erickarla Bezerra de; LIMA, Erickinson Bezerra de. Práticas didático-pedagógicas no ensino remoto: Desafios e possibilidades na Licenciatura em Teatro. Urdimento - Revista de Estudos em Artes Cênicas, Florianópolis, v. 3, n. 42, dez. 2021.

do) DOI: http:/dx.doi.org/10.5965/1414573103422021e0111

Este artigo passou pelo Plagiarism Detection Software| iThenticate 


\title{
Práticas didático-pedagógicas no ensino remoto: Desafios e
} possibilidades na Licenciatura em Teatro ${ }^{1}$

\author{
Erickaline Bezerra de Lima² \\ Erickarla Bezerra de Lima $^{3}$ \\ Erickinson Bezerra de Lima ${ }^{4}$
}

\begin{abstract}
Resumo
Este artigo objetiva problematizar o processo de ensino-aprendizagem frente às limitações e possibilidades que o ensino remoto nos oferece. Apresentamos as escolhas didático-pedagógicas desenvolvidas para as disciplinas de História do Teatro Brasileiro I e III, do curso de Licenciatura em Teatro de uma universidade pública brasileira. A partir de um questionário aplicado nas duas turmas, foi possível compreender a dimensão e efetividade das práticas desenvolvidas em consonância com as necessidades e perfil das turmas. Espera-se que as discussões fomentadas possam contribuir com as reflexões sobre a qualidade do ensino no atual momento, principalmente no que se refere à formação no Ensino Superiori.
\end{abstract}

Palavras-chave: Ensino remoto. Pandemia. Teatro. Práticas didático-pedagógicas. Ensino Superior.

\section{Didactic-pedagogical practices in remote teaching: challenges and possibilities in the Degree in Theater}

\begin{abstract}
This article aims to problematize the teaching-learning process in view of the limitations and possibilities that remote teaching offers us. We present the didacticpedagogical choices developed for the disciplines of History of the Brazilian Theater I and III, of the Theater Degree at a public Brazilian university. From a questionnaire applied to both classes, it was possible to understand the dimension and effectiveness of the practices developed in line with the needs and profile of the classes. It is hoped that the discussions fostered can contribute to reflections on the quality of education at the present time, especially with regard to training in Higher Education.
\end{abstract}

Keywords: Remote education. Pandemic. Theater. Didactic-pedagogical practices. University education.

${ }^{1}$ Revisão ortográfica e gramatical do artigo realizada por Larize Bezerra de Melo.

2 Doutoranda em Psicologia. Mestrado em Artes Cênicas pela Universidade do Rio Grande do Norte (UFRN). Professora do Departamento de práticas educacionais e currículo (DEPEC - Centro de Educação/UFRN). erickalinelima@hotmail.com

(9) http://lattes.cnpq.br/1061452525627411 (iD https://orcid.org/0000-0002-9852-4237

${ }^{3}$ Bacharelado em Ciências Sociais e em Música pela Universidade Federal do Rio Grande do Norte (UFRN). erickarlalima@windowslive.com

(9) http://lattes.cnpq.br/3140419833335308 (iD https://orcid.org/0000-0002-8256-3469

${ }^{4}$ Doutorado em Regência pela Universidade de Aveiro, Portugal. Professor da Universidade Estadual do Paraná. Pós-doutorando - PPGMUS/UFRN. eblima02@gmail.com

(9) http://lattes.cnpq.br/8299809607471071 (iD) https://orcid.org/0000-0002-4749-3899 
Prácticas didáctico-pedagógicas en la enseñanza a distancia: retos y posibilidades en la Licenciatura en Teatro

\section{Resumen}

Este artículo tiene como objetivo problematizar el proceso de enseñanzaaprendizaje ante las limitaciones y posibilidades que nos ofrece la enseñanza a distancia. Presentamos las opciones didáctico-pedagógicas desarrolladas para los cursos de Historia del Teatro Brasileño I y III de la Licenciatura en Teatro en una universidad pública brasileña. A partir de un cuestionario aplicado a ambas clases, fue posible comprender la dimensión y efectividad de las prácticas desarrolladas de acuerdo con las necesidades y perfil de las clases. Se espera que los debates propiciados contribuyan a reflexionar sobre la calidad de la educación en la actualidad, especialmente en lo que respecta a la formación la Educación Superior.

Palabras-clave: Educación a distancia. Pandemia. Teatro. Prácticas didácticopedagógicas. Educacíon superior. 
A crise sanitária provocada pelo Novo Coronavírus (SARS-CoV-2), ou COVID19, desde o fim do ano de 2019, tem provocado intensas mudanças nos modos de vida da sociedade, atingindo diferentes setores e classes sociais com menor ou maior intensidade, expondo desigualdades e fragilidades do sistema capitalista na estrutura social (Santos, 2020). No contexto educacional, as mudanças implicaram em uma necessária adequação das formas de ensino e, principalmente, exigindo dos estudantes e professores a migração em massa do presencial físico para o campo virtual. Tal prerrogativa esbarrou em uma série de dificuldades, dentre as quais: (I) técnicas, de garantia de acesso a todos os estudantes às tecnologias, ferramentas e plataformas online de ensino, semelhantes às do Ensino à distância (EaD); e, (II) pedagógicas, nos modos de ensinar e aprender adequados à presença virtual, em encontros síncronos e assíncronos, e outras alternativas (Alonso e Silva, 2018; Gusso et al, 2020).

O desafio dos educadores, nos seus diferentes níveis de ensino, é lidar com esta nova realidade e fornecer a continuidade da formação dos estudantes, de forma efetiva e, ao menos, qualitativamente equivalente. No Ensino Superior, esse desafio se configura em aulas remotas por meio de plataformas online, tais como Google Meet, Zoom e/ou Skype, que permitem a presença virtual síncrona e, nestas, o compartilhamento de ideias, orientações, debates e discussões. De maneira assíncrona, há o compartilhamento, por meio virtual, de materiais audiovisuais, livros em PDF, artigos científicos de fácil acesso, dentre outros.

Continua sendo possível realizar as mesmas práticas avaliativas, com atividades escritas via Word e apresentação de trabalhos com exposição em Powerpoint. É comum a utilização do sistema web de gestão de ensino das próprias universidades, além de outras plataformas como a ClassRoom (Google Sala de aula) e as comunidades virtuais utilizadas na organização e gerenciamento das disciplinas, no compartilhamento de materiais e informações específicas sobre as aulas, no registro de notas e frequências dos(as) alunos(as), no contato com a turma, dentre outras. A comunicação tornou-se intensificada, ainda, pelo envio e recebimento de mensagens via E-mail, WhatsApp e Messenger, com formação de grupo das disciplinas, para contato frequente entre professor(a)- 
aluno(a) e aluno(a)-aluno(a).

Para além destes recursos, os atravessamentos psicossociais que ressoam em decorrência do COVID-19, afetam severamente o progresso do ensinoaprendizagem dos(as) alunos(as) no modelo remoto. A presença de discentes trabalhadores em home office, discentes em luto, aqueles com dificuldades de aprendizagem de ordens diversas (que são agravadas pelo modo de ensino adotado) e os adoecidos por COVID-19 - são algumas das problemáticas que o(a) professor(a) enfrenta em suas práticas didático-pedagógicas nos tempos atuais. Não obstante, se acumulam ao trabalho intensificado dos(as) docentes as exigências para obter domínio das tecnologias, a carga de estresse provocada pela pandemia e os deveres familiares e domésticos (Santos, Silva, Belmonte, 2020).

Diante desse panorama de ensino-aprendizagem na pandemia, os seguintes questionamentos regem a proposta deste artigo: Será esse o máximo que conseguimos propor em formato remoto, enquanto educadores e professores, aos nossos(as) alunos(as)? Seriam essas ações suficientes para manter a qualidade que tínhamos anteriormente?

Neste artigo, iremos problematizar tais questões tendo por base a experiência vivenciada na docência do curso de Licenciatura em Teatro de uma universidade pública brasileira, a partir das disciplinas de História do Teatro brasileiro / e III. As escolhas didático-pedagógicas, para os respectivos componentes, foram organizadas e elaboradas em consonância com as características do curso, da disciplina e do perfil da turma. Neste último, observou-se o nível acadêmico, a quantidade de discentes, os conteúdos a serem ministrados e o formato remoto das aulas e atividades. Entende-se esse processo como ativo e crítico, inerente à própria natureza investigativa da prática docente, que deve estar acionada a qualquer tempo, a fim de garantir práticas criativas e inovadoras em todas as situações (Prandi, 2009).

As duas disciplinas, de caráter obrigatório, totalizaram 60h de carga horária, e foram ofertadas no período 2020.2, realizado entre 19 de janeiro e 30 de abril de 2021. O referido semestre letivo foi criado para compensar o regular suprimido em decorrência das restrições sanitárias no ano anterior. Foram desenvolvidas 58 
aulas, com quatro horários de 50 min cada, divididos em dois dias. Optou-se pelos seguintes formatos de aulas: assíncronas (29 aulas), com atividades e leituras a serem realizadas sem necessariamente haver a presença da professora; e, aulas síncronas (29 aulas), em que a turma e a professora se encontrariam para debates, aulas expositivas-dialogadas e apresentações dos trabalhos, com duração máxima de 1 h40min.

Para entendimento amplo da discussão aqui proposta, serão tecidas reflexões sobre as escolhas didático-pedagógicas no que se refere, principalmente, à metodologia e avaliações, as quais serão descritas e analisadas. Para tanto, dispomos dos conteúdos do Questionário sobre a Experiência com Ensino Remoto, produzido pelos autores do artigo e aplicado junto às duas turmas, via Google Forms. Através dele foi possível destacar a percepção dos(as) discentes acerca da experiência de estudo no semestre letivo em seu sentido geral e, especificamente, em relação a disciplina.

\section{Limitações e possibilidades do ensino no espaço-tempo da virtualidade}

No contexto da pandemia estabelecida nos últimos dois anos, provocada por um vírus altamente contagioso e letal ${ }^{5}$, medidas de segurança foram criadas e amplamente recomendadas pela Organização Mundial de Saúde (OMS), dentre elas, o distanciamento e isolamento social para controlar a rápida propagação do COVID-19 (Santos, 2020). Tendo que conviver com medidas restritivas de circulação e convívio, todas as atividades humanas, sem exceção, foram substancialmente afetadas e os hábitos de vida se transformaram. Na área da Educação, as práticas pedagógicas saíram dos espaços físicos das escolas e universidades para ocupar o espaço-tempo da virtualidade, exigindo que todos aprendessem na prática cotidiana, como lidar com desafios, limitações e possibilidades que o modelo remoto apresenta (Seabra, Aires e Teixeira, 2020).

\footnotetext{
${ }^{5}$ No primeiro ano do COVID-19 no mundo, identificou-se que ele apresentava alta letalidade em pessoas com doenças crônicas e/ou idosas (Huilan, Sheng, Shiqi, Anwen \& Jifang, 2020). Porém, a partir de 2021, constatou-se novas variantes do vírus com maior contágio, trazendo um quadro clínico de agravamento entre jovens sem comorbidades.
} 
É importante considerar que o Ensino Remoto Emergencial difere das modalidades de Ensino à distância (EaD) (Rondini, Pedro e Duarte, 2020). Pois, esta última, além de ser estruturada para tal formato, lida com um material diversificado e articulado. A proposta é de que o(a) aluno(a) se aproprie da sua autonomia para transitar pelos materiais, construindo seu caminho de aprendizagem, horário de estudo e, se preciso, recorrer a um tutor para orientálo. Por outro lado, o formato de Ensino Remoto, adotado na realidade da pandemia, situa os seus interlocutores, professor(a) e alunos(as), no mesmo espaço-tempo, mediado principalmente pelas plataformas digitais online, em uma espécie de videoconferência em tempo real, conhecido também por momento síncrono.

Diante dessa realidade, no que tange ao Ensino Superior, Guso (et al, 2020, p.5) levanta a hipótese de que:

\begin{abstract}
Embora ainda não se possa evidenciar os efeitos do Ensino Emergencial Remoto, é possível que consequências sejam percebidas nas instituições que o adotaram já com o fim do primeiro semestre acadêmico afetado pela pandemia. Como exemplos de possíveis consequências estão: a) baixo desempenho acadêmico dos estudantes; b) aumento do fracasso escolar; c) aumento da probabilidade de evasão do Ensino Superior; e, d) desgaste dos professores, que estiveram sobrecarregados pelas múltiplas atividades e pelos desafios de lidar com a tecnologia a fim de promover o ensino.
\end{abstract}

De fato, as exigências se mostram necessárias no que se refere à capacitação de professores, acesso e domínio tecnológico, frente a uma realidade brasileira que já demonstrava dificuldades em democratizar as tecnologias educacionais ou inclusão digital da população. Nesse sentido, há a propensão de ocorrerem práticas pedagógicas "bancárias", de mera transmissão do conhecimento, tornando-se densas e pouco significativas à formação. Este fato pode se configurar como o maior risco do formato remoto de ensino, ou seja, um "Ensino Tradicional Remoto". Sobre estas possibilidades, concorda-se com o exposto por Guso (et al, 2020, p.10), quando ele explicita que:

A mera transposição de aulas expositivas, com giz e quadro-negro (ou os seus correlatos "modernos", como os slides do PowerPoint), para plataformas digitais é insuficiente para garantir a "qualidade do Ensino Superior" ou, mais precisamente, para garantir o desenvolvimento de 
comportamentos profissionais de nível superior. Outras possibilidades mais promissoras, a ser realizadas tanto no ensino presencial quanto no ensino remoto, consistem, por exemplo, no ensino por projetos, por problemas, por competências; nas metodologias inspiradas em Paulo Freire; metodologias ativas etc. Além disso, feedbacks constantes têm sido eficazes na promoção de aprendizagem dos estudantes.

Sobre essa égide, autores como Freire (2006) e Libâneo (1999) já enfatizavam que os professores, como sujeitos históricos, se capacitam continuamente em sua atividade, devido à articulação indissociável entre a educação e a sociedade. Porém não quer dizer que este processo formativo seja linear e sempre consistente, pelo contrário, são tomados por experimentos, reflexões, erros e acertos para desenvolver uma prática significativa. Obviamente, não podemos generalizar, pois nem todos os professores e professoras lidam de maneira criativa ou inventiva em momentos de crise e inconsistência, como a que vivemos atualmente. Acerca do professor universitário, nota-se o exposto por Prandi (2009, p.139):

Na realidade, o professor universitário deve estar atento ao fato de que o sistema social faz exigências ao sistema educacional, que acaba por determinar os fins da educação. A partir daí, cabe-lhe a importante missão de refletir sobre tais exigências, identificando aquelas que devem ser satisfeitas e aquelas que devem sofrer influências transformadoras por parte do seu trabalho. Posteriormente, deverá pensar na formulação de objetivos, seleção e planejamento de conteúdos e metodologias adequadas para o desenvolvimento do processo de ensinoaprendizagem.

Dessa forma, a didática como campo de conhecimento e saberes próprios da relação teoria e prática, se mostra de extrema necessidade para que o(a) docente não reduza suas ações pedagógicas ao simples deslocamento do presencial físico para o presencial virtual. Ou ainda, correr o risco de se adentrar no mundo virtual profundamente, esquecendo-se que o curso/disciplina foi construído sob premissas do ensino presencial físico e nem todos(as) os(as) alunos(as) apresentarão facilidade de se adaptar a um formato semelhante ao EaD. Para não cair em extremismos em uma situação excepcional, o(a) docente necessita manter o olhar crítico sobre sua prática, atento para um iminente retorno, seja ele um possível formato híbrido ou totalmente presencial físico.

No contexto atual, há o esforço maior em que é preciso o(a) docente se 
apropriar dos materiais e ferramentas digitais de forma coerente à sua disciplina. Sobre isso, nos estudos de Rondini, Pedro e Duarte (2020), averigua-se que, na percepção dos(as) professores, ocorre uma maior facilidade no trabalho remoto de determinadas disciplinas, em detrimento de outras. Apesar do mencionado estudo se constituir da realidade da Educação Básica, em disciplinas de áreas díspares, podemos expandir a reflexão a outros contextos, inclusive ao Ensino Superior. Com isso, nos vem a reflexão de que as ferramentas tecnológicas, por si sós, não são suficientes para garantir processos de ensino-aprendizagem satisfatórios, sendo preciso saber utilizá-las, no sentido amplo do termo, considerando o perfil dos(as) alunos(as), o planejamento, a metodologia e o diálogo (Almeida, 2015).

No contexto artístico, inclui-se outras questões de ordem operacional em confronto com as características da linguagem. No caso do Teatro, por se tratar de uma arte coletiva, pautada na presença, no encontro e caracterizada pela efemeridade, pressupõe-se entre outros aspectos: processos criativos à distância com o grupo; conflitos com as limitações das plataformas; materiais filmados; e o receio de haver delay ou outros problemas relacionados a conexão da Internet em apresentações remotas. Por outro lado, os(as) artistas têm investigado as possibilidades e encontrado alternativas para criação na virtualidade, na descoberta de um novo corpo cênico e modos de agir sobre o público on-line (Lopes, 2020; Oliveira, 2020).

\begin{abstract}
Essas discussões apontam para reflexões no âmbito das novas configurações de convívio entre artistas, alunos e espectadores, a partir de outras relações entre espaço e tempo nas artes da cena, por exemplo, pela aproximação entre as linguagens do teatro e do cinema e pela utilização do recurso da live streaming (Gomes, 2021, p.9).
\end{abstract}

Tais premissas se apresentam como realidade no contexto dos estudantes dessa linguagem, em articulação com as disciplinas que trazem as dimensões teórico-práticas, reconstruindo o elo amparado na mediação teatral (Pupo, 2011). Assim, "é considerado procedimento de mediação toda e qualquer ação que se interponha, situando-se no espaço existente entre o palco e a plateia" (Moraes, 2019, p.207). Esse processo, no atual contexto, se realiza principalmente entre as 
plataformas digitais e equipamentos que se interpõe na ação dos sujeitos envolvidos.

Portanto, exige-se ações didático-pedagógicas do(a) professor(a) que, mediadas pela tecnologia, possam auxiliar na qualidade do processo de ensinoaprendizagem. Apesar de muitos(as) professores e alunos(as) considerarem o ensino remoto um terreno hostil, as descobertas das potencialidades, mesmo com seus riscos, podem permitir que haja aprendizagem qualitativamente satisfatória. Veremos no tópico a seguir, como se deu uma experiência no ensino remoto.

\section{Propostas didático-pedagógicas para ensino remoto em História do Teatro}

Constata-se, cada vez mais, que procedimentos didáticos e metodológicos peculiares ao modo presencial físico, apenas foram migrados para os ambientes virtuais. Por outro lado, aqueles que pouco utilizam recursos tecnológicos, viramse incipientes frente à repentina necessidade de suprir a realização das atividades de forma remota (Rondini, Pedro e Duarte, 2020). Essa realidade possui a essência de interação virtual - seja por parte do(a) docente, ou do(a) aluno(a). Em síntese, será que as estruturas político-pedagógicas de ensino são capazes de promover a autonomia discente no contexto remoto? Que metodologias de ensino e aprendizagem seriam promotoras dessa autonomia? Qual seria a percepção crítica do(a) aluno(a) perante o contexto remoto?

Para a formação dos(as) estudantes do curso superior de Licenciatura em Teatro, na modalidade presencial, se concebe a interlocução das práticas pedagógicas aos saberes artísticos teatrais, situando os estudantes em meio às aulas teórico-práticas, projetos de ensino, pesquisa e extensão. Mediante as Diretrizes Curriculares Nacionais do curso de Graduação em Teatro, proposto pelo Conselho Nacional de Educação (CNE) - na Resolução na 4 de 8 de Março de 2004, se expõe detalhadamente no art. 2ª , o seguinte:

A organização do curso de que trata esta Resolução se expressa através do seu projeto pedagógico, abrangendo o perfil do formando, as competências e habilidades, os componentes curriculares, o estágio 
curricular supervisionado, as atividades complementares, o sistema de avaliação, a monografia, o projeto de iniciação científica ou o projeto de atividade, como trabalho de conclusão de curso - TCC, componente opcional da instituição, além do regime acadêmico de oferta e de outros aspectos que tornem consistente o referido projeto pedagógico.

Pela natureza do documento, derivam-se pontos norteadores para estruturação do projeto pedagógico do Curso. Assim, as instituições de Ensino Superior delineiam suas propostas em conformidade com a realidade local, considerando o alcance da atuação profissional e outros aspectos contextuais, na decisão, por exemplo, de vagas e modalidades. Dessa forma, destaca-se esse ponto em confronto com a emergência do ensino remoto, na reflexão de como deve-se dar continuidade aos objetivos pretendidos à formação, especificados em projeto. Para esta problematização, utilizou-se como objeto de estudo, as disciplinas de cunho teórico e obrigatório de História do Teatro Brasileiro I (HTBI) e III (HTBIII), dois níveis de ensino distintos, direcionadas respectivamente à turma do 2a e 4a períodos. Tais turmas, no período suplementar $2020.2^{6}$, encontravamse respectivamente com 32 e 45 discentes matriculados.

Para a disciplina HTBI, houve a presença assídua de um aluno na condição de monitor, selecionado por projeto de Monitoria específico para a disciplina, aprovado em edital da Instituição - na condição de voluntário. O discente auxiliou nas demandas técnicas, na facilitação da comunicação entre professoraalunos(as), do planejamento à execução, o que agregou a ele a aprendizagem extensiva em torno da docência no Ensino Superior.

Ambas as disciplinas partem do mesmo pressuposto, de promover o conhecimento acerca dos elementos históricos-sociais que abrangem a constituição da arte teatral no Brasil, perpassando os diferentes períodos e contextos culturais. Para estes componentes, tem-se a defesa de uma compreensão dialética ao envolver obra-artista-sociedade, a fim de ser possível problematizar os fatos, personalidades, imaginário social, constituição estética e técnicas das obras produzidas, em sua base contextual (Magaldi, 2004). Tal

${ }^{6}$ Devido ao estado de calamidade provocado pela pandemia, várias Instituições de Ensino Superior tiveram que reorganizar seu calendário acadêmico, a fim de incluir o(s) semestre(s) suprimido(s) de 2020. No caso, o semestre 2020.2 foi incluído no ano seguinte, no período de 19 de janeiro a 30 de abril de 2021. 
panorama se mostra igualmente coerente com a perspectiva de ensino em artes defendida por Ana Mae Barbosa (2012), no cerne da abordagem triangular, no movimento de fazer, contextualizar e apreciar, ou seja:

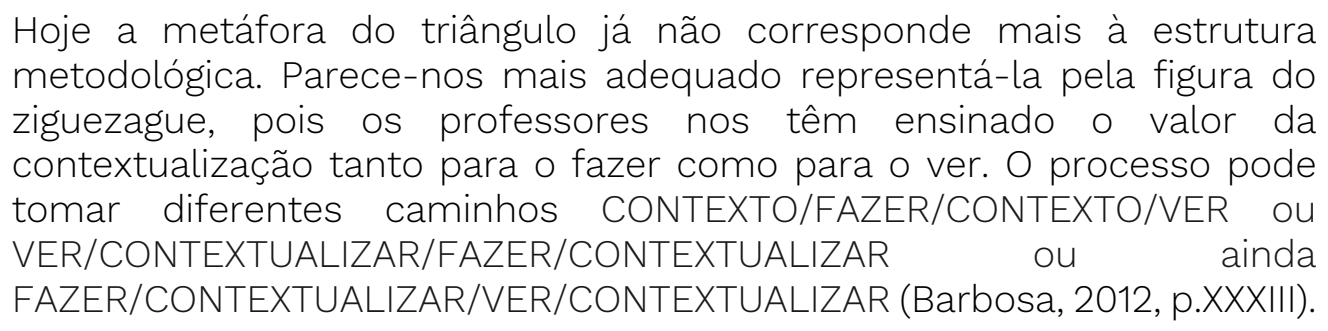

Seguindo esse ideal ao encontro de uma aprendizagem significativa, formatase as estratégias didático-pedagógicas, considerando a modalidade remota, em seus desafios e possibilidades. Assim, o ensino das mencionadas disciplinas adequou-se na sistematização de aulas expositivas dialogadas, com utilização de textos acessíveis, principalmente artigos científicos, que foram disponibilizados no sistema de gestão de atividades acadêmicas da instituição. A partir desse mesmo portal, houve a utilização da comunidade virtual, onde foi possível gerenciar a produção dos(as) discentes, ao mesmo tempo que puderam compartilhar os textos críticos por meio de fóruns virtuais, tornando-os visíveis a todos. Uma atividade avaliativa comum às duas disciplinas, consistia no estudo de obras dos períodos abordados no componente curricular, com exigências de adaptar criativamente, no formato cênico-virtual, e pesquisar elementos históricos.

O perfil da turma de HTBI constituía-se de recém-ingressantes do ano de 2020. Eram discentes que, nos primeiros meses do curso, tiveram que se afastar do cotidiano acadêmico presencial, tendo seu processo de adaptação ao Ensino Superior anexado a um novo processo: adequação ao Ensino Remoto. O conteúdo de HTBI, compreendia: introdução à historiografia teatral, períodos pré-coloniais, teatro catequético e as práticas teatrais desenvolvidas até a primeira metade do século XX. A primeira avaliação consistia na pesquisa e leitura de artigos científicos que tivessem por temática qualquer um dos conteúdos abordados na disciplina, e que fossem produções atuais, dos últimos 5 anos. Ou seja, os(as) alunos(as) tiveram a experiência de como pesquisar em bases de dados confiáveis, tais como: Portal de Periódicos Capes, Google Acadêmico e sites de revistas especializadas 
na área, adquirindo assim, um conhecimento necessário para disciplinas futuras do curso. Em seguida, eles(as) fizeram uma breve resenha crítica sobre o material lido.

Para outra avaliação da disciplina, foram disponibilizadas as obras: Antônio José, ou o poeta e a inquisição (1838), de Gonçalves Magalhães (1811-1882); Judas em Sábado de aleluia (1840), de Martins Pena (1815-1848); A jóia (1879), de Arthur Azevedo (1855-1908); O romance de uma velha (1870), de Joaquim Manoel de Macedo (1820-1882); Mãe (1860), de José de Alencar (1829-1877); e, por fim, A separação de dois esposos (1866), de Quorpo Santo (1829-1883). Os(as) alunos(as) se organizaram em grupos de trabalho, com 5 ou 6 integrantes para cada obra, com o objetivo de apresentar uma adaptação cênica-virtual de um trecho. Além disso, em um segundo momento, era exposto pelos(as) discentes a contextualização acerca da obra escolhida, que envolvia dados sobre o autor, encenações já produzidas, pesquisas sobre a estética da obra e relatos sobre a experiência de adaptá-la. Como Rizzi destaca (2007, p.64):

Ao contextualizar estamos operando no domínio da História da Arte e outras áreas do conhecimento necessárias para determinado programa de ensino. Assim estabelecem-se relações que permeiam a interdisciplinaridade no processo de ensino-aprendizagem.

A dimensão criativa mobilizada pelos(as) alunos(as) ao terem a experiência de adaptar cenicamente a obra, sugere a interdisciplinaridade em essência, ao lidarem com outras práticas teatrais intrínsecas à ação de produzir, tais como: dramaturgia, cenografia, iluminação, figurino e atuação, dentre outros temas e disciplinas do currículo do curso. De forma a interligar a tríade, sendo que "Contextualizar é estabelecer relações [...] a contextualização no processo ensinoaprendizagem é a porta aberta para a interdisciplinaridade” (Barbosa, 1998, p.38).

Mediante esse processo, é importante elucidar que a metodologia utilizada permitiu à turma o contato com diferentes obras dos períodos estudados. A cada apresentação era solicitado que os(as) discentes escrevessem um comentário sobre a obra assistida, utilizando como canal de publicação a comunidade virtual no tópico do fórum destinado à obra apreciada. A troca de comentários a partir 
deste canal, se mostrou eficaz para a interação entre os estudantes, na organização e elaboração de escrita crítica, como também para consolidar a experiência de registro, já que se tratava de disciplinas de História. Estes são elementos que nos aproximam novamente da abordagem de Barbosa (2012), na dimensão de apreciar criticamente o que foi produzido pelos(as) colegas.

Em HTBIII, disciplina oferecida ao 4ạ período do curso, os conteúdos giravam em torno da politização do teatro, indo em direção a temas e discussões contemporâneas sobre teatro-sociedade, grupos e tendências artísticas (Faria, 2012). Neste componente, houve a participação heterogênea de discentes de períodos distintos. Uma demanda nascente de uma mudança curricular do curso, que deslocou a disciplina de História do Teatro brasileiro III da dimensão optativa para a obrigatória.

Em termos didático-pedagógicos, somente algumas diferenças foram introduzidas em relação à turma de HTBI. A primeira delas se deve à formação de grupos de trabalhos maiores para estudo de obras e produções situadas na segunda metade do século XX, a saber: Cordélia Brasil (1969), de Antônio Bivar (1939-2020); Santidade (1967), de José Vicente (1945-2007); No que vai dar isso (1994), de Plínio Marcos (1935-1999); O rato no muro (1967), de Hilda Hilst (19302004); Liberdade, Liberdade! (1965), de Millôr Fernandes (1923-2012) e Flávio Rangel (1934-1988); e, O santo e a porca (1957), de Ariano Suassuna (1927-2014).

Para a adaptação/leitura dramática, em ambas as disciplinas os(as) discentes tiveram total liberdade para desenvolver a parte criativa da proposta. Dessa forma, destacam-se, entre as escolhas realizadas pelos(as) discentes na execução desta atividade: leitura dramática tradicional, ocorrendo remotamente no horário síncrono da aula; o trabalho cênico-virtual "ao vivo", com inserção ou não de partes gravadas; e, adaptação inspirada na obra dramatúrgica apresentada remotamente.

Nas duas disciplinas, como apoio para melhor distribuição das notas e conceitos, por parte da docente, foram produzidas fichas avaliativas, contendo os critérios adotados para análise da atividade de adaptação cênica-virtual, contemplando três eixos: (I) aspectos técnicos, considerando pontualidade e organização; (II) trabalho criativo, com critérios acerca da construção estética, 
qualidade interpretativa e execução da proposta do grupo; e, (III) contextualização, a englobar síntese da pesquisa de criação realizada, com fontes e materiais históricos sobre artista-obra e relato de cada integrante sobre o processo criativo. Após a avaliação realizada pela professora, com base em tais critérios, essa ficha foi entregue ao discente/grupo a fim de contribuir para a conscientização das potencialidades e fragilidades do trabalho, devolutiva que garantiu uma maior transparência ao processo avaliativo.

Na turma de HTBIII não foi utilizada a comunidade virtual, do próprio sistema de gestão de atividades acadêmicas. Mas, através do Google Forms, a turma pôde tecer comentários sobre a apresentação dos colegas, caso não tivessem tempo para comentar "ao vivo". Após a aula, os comentários eram listados anonimamente em PDF e disponibilizados à turma para que todos(as) pudessem ter acesso ao feedback.

Além dessas diferenças, uma das ações da disciplina (HTBIII) foi o encontro com grupos de teatro em atividade no Brasil, sendo 4 convidados distribuídos nas últimas semanas de aula síncrona. Estas aulas se configuraram como "aula aberta”, com ampla divulgação nas redes sociais do curso, oportunizando a participação de outros(as) discentes e demais interessados. Para esta etapa, contou-se com a presença de: Candeeiro (Rio Branco-Acre); Teatro das Cabras (Natal - Rio Grande do Norte); Quem tem Boca é para Gritar (João Pessoa Paraíba); e, por fim, o grupo Girino (Belo Horizonte - Minas Gerais).

Cada grupo convidado apresentou sua trajetória, experiência, as características estéticas de suas obras, situações vividas, desafios frente ao contexto de pandemia - dentre outras - o que enriqueceu ainda mais as discussões já introduzidas nas aulas expositivas-dialogadas do início do semestre letivo. No mais, novos conteúdos foram suscitados de forma mais próxima à realidade, pela vivência direta da prática teatral dos convidados. Ter um espaço para grupos teatrais, se mostrou alternativa bastante eficaz mediante o contexto, permitindo o diálogo que ultrapassa as barreiras geográficas.

Esta proposta não se tratou de um mero encontro, mas foi integrada como parte da avaliação para nota, considerando a presença e a participação com 
pergunta ou comentário. Para controle dessa participação, foi utilizado o Google Forms, para registro do nome e a elaboração do texto endereçado ao convidado. A ferramenta utilizada garantiu que os(as) alunos(as) tivessem diferentes possibilidades de participação.

Eventualmente, devido ao tempo de aula, nem todas as perguntas ou comentários conseguiram ser feitos durante o encontro. Nesse sentido, o material era repassado aos convidados em documento PDF, após a aula. A partir disso, haveria a possibilidade dos grupos darem continuidade, respondendo os questionamentos em suas redes sociais (Instagram/ Facebook). Prerrogativa que fez os(as) alunos(as) acompanhar e conhecer ainda mais o trabalho desenvolvido pelos(as) artistas, além de movimentar as redes sociais e a visibilidade dos grupos.

É importante mencionar que a comunicação professor(a)-aluno(a) tende a se fragilizar consideravelmente nos processos de ensino remoto (Guso et al, 2020). Por isso a utilização de vias alternativas como os aplicativos Messenger ou WhatsApp, na criação de grupo específico da disciplina, pode subsidiar as trocas de informações para além do e-mail. Estes canais podem auxiliar na organização das atividades e repasse delas, e, portanto, podem ser utilizados como suporte informacional em todos os procedimentos didático-pedagógicos.

Foi perceptível que a dinâmica proposta em ambas as disciplinas garantiu uma maior adesão dos(as) alunos(as) às atividades, tornando-os mais motivados a criarem, experimentarem as obras e os estudos contextuais acerca delas. Em tempos de pandemia, os(as) artistas vivenciam um processo de adequação artística ao modo de criação no espaço-tempo da virtualidade, redescobrindo possibilidades de continuar em atividade (Oliveira, Melo, 2021). Podemos considerar que os(as) estudantes de teatro - muitos atuantes no cenário artístico vislumbraram possibilidades a partir da disciplina, não somente ao adaptarem as obras sugeridas, mas também ao assistirem os(as) colegas e suas escolhas criativas, tornando a disciplina um laboratório de criação autêntico, acerca de um iminente Teatro Virtual. 


\section{Análise do processo de ensino-aprendizagem no modelo remoto}

Para uma maior compreensão do processo de ensino-aprendizagem, considerando a dinâmica proposta e o perfil do alunado, construiu-se um questionário ${ }^{7}$ de avaliação da experiência sobre a disciplina, pelo qual foi possível proferir análises. Este foi aplicado via Google Forms nas turmas de História do Teatro Brasileiro, na última semana de aula, sendo facultativa a participação. O questionário totalizou 26 questões, sendo 7 dissertativas, com uma opcional para eventuais sugestões e, possuía: Termo de Consentimento Livre e Esclarecido (TCLE) $)^{8}$; perguntas sobre o contexto acadêmico; perfil socioeconômico; autoavaliação da aprendizagem; e, por fim, avaliação sobre a disciplina em que esteve matriculado. Foi preservado o anonimato dos(as) discentes.

Obteve-se o número de 70 respostas válidas, o que corresponde à adesão de 90,9\% em relação ao total de alunos(as) matriculados(as) nas disciplinas. Sendo, 37,1\% dos respondentes de História do Teatro Brasileiro I; $60 \%$ referente a História do Teatro Brasileiro III; e 2,9\% estavam matriculados(as) nos dois componentes do curso. Além disso, outros aspectos foram contemplados, como está expresso na tabela 1 a seguir, que nos aproxima da realidade socioeconômica dos(as) alunos(as):

${ }^{7}$ Questionário produzido pelos autores do artigo.

8 O termo era consentido no próprio formulário, como quesito obrigatório para responder às questões seguintes. Não houve necessidade de ser submetido ao Comitê de Ética da instituição, por não se configurar como projeto de pesquisa, mas direcionado ao aperfeiçoamento da prática pedagógica. 
Tabela 1 - Perfil socioeconômico dos(as) alunos(as) matriculados(as) em HTB I e III

\begin{tabular}{lcc}
\hline Variáveis & n $\underline{a}$ & $\%$ \\
Gênero: & 27 & $38,6 \%$ \\
Homem & 37 & $52,9 \%$ \\
Mulher & 6 & $8,6 \%$ \\
Não-binário & 13 & $18,6 \%$ \\
Faixa-etária & 47 & $67,1 \%$ \\
Menos que 20 anos & 7 & $10 \%$ \\
21 a 30 anos & 3 & $4,3 \%$ \\
31 a 40 anos & & $4,3 \%$ \\
Acima de 41 anos & 3 & $4,3 \%$ \\
Possui filho(a)(s) & 3 & $91,4 \%$ \\
Um filho(a) & 64 & $45,7 \%$ \\
Dois ou mais & & $4,3 \%$ \\
Não possui & 32 & $1,4 \%$ \\
Emprego (formal ou informal) & 3 & $48,6 \%$ \\
Trabalha e estuda & 1 & \\
Trabalhou no início do semestre letivo & 34 & $44,4 \%$ \\
Trabalhou ao final do semestre letivo & & $13,9 \%$ \\
Somente estuda & & $41,7 \%$ \\
\hline Horário de Trabalho conflitou com o & 16 & 5 \\
horário da(o) disciplina/curso & 15 & \\
Parcialmente & & \\
Totalmente & & \\
Não. Contraturno & &
\end{tabular}

Tabela produzida pelos autores do artigo

A tabela 1 apresenta um panorama da realidade social vivida pelos(as) alunos(as), pontos cruciais que ajudam a melhor direcionar as ações pedagógicas. Informações como estas podem ser obtidas no desenvolvimento da relação professor(a)-aluno(a), no decorrer do semestre letivo e no primeiro dia de aula. Deve-se destacar o fato de mais da metade dos(as) alunos(as) da disciplina estarem trabalhando ou terem trabalhado em algum momento do semestre letivo, somados as duas condições correspondem a 36 alunos(as) (equivalente a 51,4\%). A dupla jornada estudo-trabalho, em muitos casos, pode comprometer o andamento do processo de ensino-aprendizagem, pela falta de assiduidade e comprometimento com as atividades, como aponta os estudos de Flor e Mercuri (2018) e Maier e Mattos (2016).

Nesse caso, umas das alternativas escolhidas para amenizar as dificuldades dos(as) alunos(as)-trabalhadores, pode estar no maior prazo para entrega ou apresentação das atividades avaliativas. Para as duas disciplinas, foi explicitado 
logo na segunda semana, quais seriam as avaliações referentes às notas das três unidades, bem como suas respectivas datas/prazos com mais de um mês de antecedência, o que facilitou o(a) aluno(a), principalmente, os(as) trabalhadores a se organizarem mediante às demandas laborais.

Com essa escolha, constatou-se uma participação homogênea dos(as) alunos(as) no processo de construção da proposta avaliativa - já descrita no tópico anterior deste artigo. Apesar disso, houve alguns alunos(as) que necessitaram de uma atividade diferenciada, por se encontrarem no horário da aula em ambiente de trabalho ou, simultaneamente, em home office, modos que impediam uma maior interação. A realidade da pandemia, principalmente a crise econômica decorrente, fez com que muitas pessoas precisassem buscar empregos para se manterem e/ou ajudar familiares (Bridi, 2020; Silva, 2020). Lidar com estudantes nessa condição pode ser considerado um dos maiores desafios em tempos de Ensino Remoto, realidade que não pode ser negligenciada pelo professor(a). Em situação semelhante, porém no interior de suas residências os(as) alunos(as) também podem ter sua atenção comprometida ou se sentirem limitados a emitir opiniões (Dosea et al, 2020).

Sobre questões acadêmicas e seus atravessamentos, os dados discriminados na tabela 2 abaixo, caracterizam o(a) discente no momento da disciplina, considerando aspectos que diretamente ou indiretamente influenciam no desempenho. Outro aspecto relevante, se trata de entender o desempenho em relação ao semestre anterior, realizado também no formato remoto, o que possibilita perceber como os(as) alunos(as) se reconhecem no processo de adaptação a este modelo de ensino. 
Tabela 2 - Perfil acadêmico dos(as) alunos(as) matriculados(as) em HTB I e III

Variáveis

Nivelados com a turma de origem

Desnivelados com a turma de origem

Qtd de disciplinas no semestre atual

Uma disciplina

Duas a quatro disciplinas

Cinco ou mais disciplinas

\section{Em relação ao semestre anterior, o número de} disciplinas foi:

Maior que no semestre anterior 30

Menor que no semestre anterior

Mesma quantidade de disciplinas

Em relação ao semestre anterior, o período atual foi:

Melhor que o semestre anterior

Pior que o semestre anterior

36

19

15
$\%$

$70 \%$

21

$30 \%$

2

$2,9 \%$

$34,3 \%$

44

$62,9 \%$

Tabela produzida pelos autores do artigo

Mediante o exposto, 30 (42,9\%) alunos(as) se matricularam em mais componentes curriculares, o que nos faz considerar que, a partir da experiência com o ensino remoto no semestre anterior, houve um processo de reconhecimento e adaptação ao modelo de ensino. O(a) aluno(a) também pode se ver na iminência de lidar com limitações impostas versus necessidade de cumprir os componentes do curso, algo que permitiu assumirem o risco de abarcar mais disciplinas no semestre seguinte. Da mesma forma, o número de disciplinas oferecidas pelo departamento também foi consideravelmente maior em relação ao semestre anterior, o que ratifica este resultado também em relação aos professores, no desafio de assumirem mais turmas.

É preciso reconhecer os outros quesitos que apresentam discentes que optaram por se matricular em menos disciplinas 27 (38,6\%), e os que permaneceram na mesma quantidade em relação ao semestre anterior 13 (18,6\%) que, somados, equivalem a 57,2\% das turmas. Nesse caso, pode-se evidenciar a 
ideia de não-adaptação ao ensino remoto, fazendo o(a) aluno(a) optar por não se matricular em mais componentes, mesmo que tenha sido oferecido um maior número de disciplinas.

Ao discutirmos sobre o ensino remoto é indispensável considerar como se configura a garantia de acesso dos(as) alunos(as) a equipamentos e internet, no semestre letivo. Uma das políticas de assistência estudantil mais comuns nas Instituições públicas de Ensino Superior, nesse período, foi o repasse de recursos para aquisição de equipamentos e/ou internet para alunos(as) de baixa renda, o que de fato se mostrou fundamental para participação destes às aulas remotas (Gusso et al, 2020). Na tabela 3, é possível compreender como se deram esses aspectos nas turmas analisadas.

Tabela 3 - Acesso dos(as) alunos(as) a equipamentos e internet

Você recebeu algum auxílio da Universidade para aquisição de equipamento e/ou acesso a internet?

Sim, Internet e equipamento

$11 \quad 15,7 \%$

Sim, apenas internet 2 $2,9 \%$

Sim, apenas equipamento

Fui apto a adquirir equipamento e/ou internet, porém não houve repasse até o momento.

Não precisei

Qual(is) equipamento(s) você utilizou para seus estudos? (pode marcar mais de uma opção)

Computador/notebook PRÓPRIO

Computador/notebook EMPRESTADO

$5 \quad 7,1 \%$

Celular smartphone PRÓPRIO

Celular smartphone EMPRESTADO

Tablet PRÓPRIO

Tablet EMPRESTADO

$\begin{array}{lc}4 & 5,7 \% \\ 0 & 0 \%\end{array}$

Tabela produzida pelos autores do artigo

De acordo com os dados obtidos referentes às turmas, 25 (35,7\%) dos(as) alunos(as) necessitaram de algum tipo de auxílio para equipamento e/ou internet. 
Caso não houvesse esse tipo de suporte da Instituição, poderia haver um desfalque considerável nas disciplinas, prejudicando o progresso acadêmico dos(as) discentes.

Em complemento a isso, na segunda questão "Qual(is) equipamento(s) você utilizou para seus estudos?" os(as) alunos(as) poderiam selecionar mais de uma opção, a fim de destacar a variedade do(s) equipamento(s) que têm à disposição para uso. Como a totalidade das respostas neste quesito somam mais de 100\%, entende-se que boa parcela das turmas tinha mais de um equipamento para utilização. Porém, apesar dos subsídios materiais se mostrarem como base para o ensino remoto emergencial, é importante salientar que, a depender do tipo do equipamento e de sua qualidade técnica, o acompanhamento das aulas e, consequentemente, o processo de aprendizagem do(a) aluno(a) pode ser prejudicado. Desse modo, dificilmente o(a) docente terá ciência total sobre a qualidade do acesso dos(as) alunos(as) às aulas, mas a atenção quanto a esse fator deve ser contínua e indispensável para que estratégias pedagógicas possam ser dirigidas a tempo de evitar maiores intercorrências.

As aulas gravadas podem se configurar como uma estratégia pedagógica, principalmente, para aqueles(as) alunos(as) que, por razão de ordem técnica, não conseguiram acompanhar as discussões da aula síncrona. Nesse caso, é interessante disponibilizar o material gravado mediante solicitação explícita do(a) aluno(a), para que o docente tenha ciência das eventuais intempéries vivenciadas pelo(a) discente. Partindo dessa premissa, não se recomenda a liberação livre das gravações, para que não haja esvaziamento nas aulas síncronas, tendo em vista a importância do encontro presencial virtual para o desenvolvimento do aprendizado, por meio de debates, diálogos e explanação das dúvidas.

Ao que se refere especificamente à experiência em HTB, o questionário apresentou seis questões subjetivas. O(a) aluno(a) responderia a partir de associação livre, no âmbito positivo, quanto negativo o seguinte eixo: "Mencione 3 fatos/aspectos/momentos que, para você, foram marcantes". Neste questionamento, o(a) respondente, com base na sua percepção pessoal, deveria refletir sobre os conteúdos e as atividades avaliativas da disciplina. A seguir, no quadro 1, são apresentadas as respostas produzidas, agrupadas por semelhanças 
em seus sentidos e conteúdos:

Quadro 1 - Perguntas subjetivas sobre a disciplina, aspectos positivos e negativos, considerando HTBI e HTBIII

\begin{tabular}{|c|c|c|}
\hline Pergunta norteadora & HTBI & HTBIII \\
\hline \multirow[t]{2}{*}{$\begin{array}{l}\text { Mencione TRÊS } \\
\text { fatos/aspectos/momentos } \\
\text { que você considera } \\
\text { marcantes acerca do } \\
\text { CONTEÚDO da disciplina }\end{array}$} & $\begin{array}{l}\text { POSITIVO } \\
\text { - Aulas especificas: Origem do } \\
\text { teatro, Teatro Ameríndio, teatro } \\
\text { jesuíta, Teatro Negro, João } \\
\text { Caetano; } \\
\text { - Utilização de documentos } \\
\text { históricos nas aulas; } \\
\text { - As pesquisas realizadas para as } \\
\text { atividades; } \\
\text { - As obras selecionadas para } \\
\text { apresentações das } \\
\text { adaptaçôes/leitura dramática } \\
\text { - As referências de leitura } \\
\text { - A apresentação dos grupos } \\
\text { sobre obra: A jóia de Arthur } \\
\text { Azevedo; A peça A mãe de José } \\
\text { de Alencar; } \\
\text { - Os processos criativos }\end{array}$ & $\begin{array}{l}\text { POSITIVO } \\
\text { - Debate e presença de grupos } \\
\text { teatrais convidados; } \\
\text { - As obras selecionadas para } \\
\text { adaptação/leitura dramática; } \\
\text { - Aulas específicas: Censura } \\
\text { teatral; As mulheres no Teatro; } \\
\text { Artista como trabalhador. } \\
\text { - Documentos históricos sobre o } \\
\text { Teatro Oficina } \\
\text { - A experiência de produzir uma } \\
\text { adaptação/leitura dramática } \\
\text { - Os slides (Powerpoint) } \\
\text { - explicativos e com imagens; } \\
\text { - As gravações das aulas à } \\
\text { disposição e o } \\
\text { compartilhamento dos slides e } \\
\text { outros materiais; }\end{array}$ \\
\hline & $\begin{array}{l}\text { NEGATIVO } \\
\text { - Ausência da participação dos } \\
\text { colegas nas aulas; } \\
\text { - Dificuldade de concentração e } \\
\text { foco; } \\
\text { - Apresentação desorganizada de } \\
\text { um dos grupos; } \\
\text { - Conteúdo excessivo; } \\
\text { - Leituras em aulas assíncronas; }\end{array}$ & $\begin{array}{l}\text { NEGATIVO } \\
\text { - Conteúdo excessivo para pouco } \\
\text { tempo; } \\
\text { - Dificuldade de trabalhar em } \\
\text { grupo no formato remoto; } \\
\text { - Falta de um debate maior } \\
\text { acerca das leituras de } \\
\text { referência sugeridas; } \\
\text { - Poucas referências regionais e } \\
\text { de autores (as) negros(as); }\end{array}$ \\
\hline $\begin{array}{l}\text { Mencione TRÊS } \\
\text { fatos/aspectos/momentos } \\
\text { que você considera } \\
\text { marcantes acerca da(s) } \\
\text { AVALIAÇÃO(ÕES) da } \\
\text { disciplina }\end{array}$ & $\begin{array}{l}\text { POSITIVO } \\
\text { - Contextualização solicitada nos } \\
\text { trabalhos; } \\
\text { - A prática teatral desenvolvida, } \\
\text { mesmo em formato remoto; } \\
\text { - Suporte do Monitor e } \\
\text { Professora; } \\
\text { - Clareza em expor as atividades } \\
\text { solicitadas; } \\
\text { - Prazos adequados à realidade } \\
\text { do(a) aluno(a) - principalmente } \\
\text { os que trabalham; } \\
\text { - Fichas avaliativas com critérios } \\
\text { adotados para nota e } \\
\text { comentários sobre o trabalho; }\end{array}$ & $\begin{array}{l}\text { POSITIVO } \\
\text { - Qualidade dos trabalhos } \\
\text { desenvolvidos; } \\
\text { - A apresentação da obra } \\
\text { Liberdade, Liberdade de Millôr } \\
\text { Fernandes e Flávio Rangel; } \\
\text { - Receber o feedback da turma } \\
\text { sobre as apresentações; } \\
\text { - Comentar sobre as } \\
\text { apresentações dos colegas; } \\
\text { - Didática e condução da } \\
\text { professora; } \\
\text { - Prazos adequados para realizar } \\
\text { com tranquilidade cada } \\
\text { atividade; }\end{array}$ \\
\hline
\end{tabular}


- Utilização da comunidade virtual, para interagir e comentar sobre as obras vistas.
- A experiência de produzir uma obra dramática e aumentar o conhecimento acerca delas;

- O contato com os grupos convidados;

\section{NEGATIVO}

- Não conseguir realizar os ensaios com todos os integrantes do grupo;

- A desistência de integrantes no meio do processo;

- Dificuldade com modelo de aulas remotas;

- Dificuldade em encontrar materiais de referência da obra teatral estudada;

- Falta de preparo de alguns grupos;
NEGATIVO

- Número de integrantes por grupo de trabalho e conseguir reuni-los:

- Dificuldade em lidar com o formato remoto

- Estar trabalhando dificultou a interatividade com as apresentações dos colegas;

- O tempo curto que impedia de realizar comentários "ao vivo".

Fonte: produzido pelos autores do artigo

Entre as respostas coletadas, há referência sobre a condição pessoal do aluno(a) na disciplina (acesso à internet, equipamento, etc.) e a dificuldade em algum conteúdo ou atividade. Como ponto positivo, foi ressaltado a dinâmica da aula e a forma da professora lidar com as situações adversas.

Além do que está explicitado no Quadro 1, foi mencionado em algumas respostas e no decorrer das disciplinas, o uso de músicas reproduzidas antes do início da aula, em coerência com o conteúdo abordado, ou a partir de playlist, com repertório de livre escolha construído coletivamente. Aspecto que, segundo os(as) alunos(as), contribuiu para o alívio do estresse, gerando maior disposição para a aula.

O Questionário sobre a Experiência com Ensino Remoto se apresenta como um instrumento importante para obter o perfil do(a) aluno(a) e de que forma as ações didático-pedagógicas o atingiram, seja positivamente ou negativamente. Ao final da disciplina, as reflexões geridas a partir deste material pode subsidiar a renovação ou aprimoramento da prática docente, principalmente no âmbito do ensino remoto. No confronto dos elementos positivos e negativos, se tem uma visão global do vivenciado pelo(a) aluno(a) no reconhecimento das duas faces dialéticas do processo de ensino-aprendizagem. Como Cadau (2000, p.89) nos diz: 
[...] o educador nunca estará definitivamente "pronto", formado, pois que sua preparação, sua maturação se faz no dia a dia, na mediação teórica sobre sua prática. A sua constante atualização se fará pela reflexão diurna sobre os dados de sua prática. Os âmbitos do conhecimento que the servem de base não deverão ser facetados, estanques e isoladas de tratamento do seu objeto de ação: a educação. Mas serão, sim, formas de ver e compreender globalmente, na totalidade, o seu objeto de ação.

As reflexões expressam que a atuação docente se constitui como um "jogo" de ação e reação. Neste "jogo”, a realidade da pandemia impõe suas regras, as quais exigem das práticas didático-pedagógicas novas abordagens e estratégias para dar continuidade aos processos formativos dos sujeitos. Isto é, fixar/fechar conceitualizações frente a uma realidade, deprecia estruturas que são dinâmicas, mutáveis e multidimensionais (Gutiérrez, 2020). Devemos estar abertos às possibilidades ou estaremos fadados a reproduções metodológicas que não são exequíveis ao contexto vivenciado.

\section{Considerações finais}

Em um contexto de pandemia provocado pelo Coronavírus (COVID-19), os modos de vida dos sujeitos foram radicalmente modificados em diferentes instâncias. Na área da Educação, professores e alunos(as) se viram no desafio de continuar suas atividades no formato presencial-virtual. Esta mudança gerou uma série de problemáticas sobre uso e acesso às diferentes tecnologias e, consequentemente, acerca da qualidade do ensino-aprendizagem atrelada a esse novo sistema.

Tais aspectos passaram a fazer parte do cotidiano de formação de discentes e professores de todo o mundo, vivenciando cada semestre letivo de ensino remoto, mediante às características teórico-práticas dos componentes curriculares e às ações pedagógicas possíveis. Para estudantes da área artística do Ensino Superior, as implicações se constituem na própria realidade profissionalartística, principalmente na experiência de produzir e apreciar. No que cerne ao Teatro, constituiu-se um processo de redescoberta da linguagem na realidade virtual, já que, em essência, a linguagem teatral é pautada na presença e na efemeridade. 
As escolhas didático-pedagógicas introduzidas nas disciplinas de História do Teatro brasileiro I e III mobilizaram os(as) alunos(as) a se envolverem com os conteúdos e avaliações, considerando a articulação do fazer-apreciarcontextualizar (Barbosa, 2012), tornando-os ativos e críticos em cada etapa do processo. Com isso, atividades dinâmicas, diversificadas e articuladas substancialmente à teoria-prática foram vias significativas na experiência com as disciplinas. Aspectos didáticos quanto a prazos para entrega/apresentação de atividades, canais para facilitar comunicação, uso de diferentes plataformas digitais, adequação da proposta avaliativa de acordo com a realidade do(a) discente e, os intercâmbios com convidados(a) na disciplina, foram relevantes para os(as) alunos(as), possibilitando relacionar os conteúdos lidos e vistos no decorrer da disciplina.

Nesse sentido, percebeu-se a partir da discussão fomentada que os(as) alunos(as) se encontram em processo de adaptação ao ensino remoto, algo que se mostrou perceptível no decorrer do semestre letivo e dos dados obtidos por meio da aplicação do Questionário sobre a Experiência com Ensino Remoto. Este instrumento se mostrou importante para a obtenção da percepção dos(as) discentes acerca dos respectivos componentes curriculares e da experiência vivida.

Os resultados evidenciados auxiliaram no aprimoramento docente, contribuindo para o processo de adaptação da professora ao formato virtual, o que pode suscitar novas práticas pedagógicas ou aprimoramento destas em disciplinas futuras (Cadau, 2000). Trata-se de uma via de mão dupla, em que tanto o(a) professora(a), quanto os(as) discentes, situados numa realidade de crise sanitária mundial, encontraram possibilidades para a eficácia e continuidade do processo formativo. E de fato, as prerrogativas apresentadas em torno das disciplinas só se tornaram efetivas pelo comprometimento dos agentes envolvidos (professora-discentes) e o acesso dos(as) alunos(as) a itens básicos para ensino remoto, equipamentos e internet.

A tendência ao Ensino Remoto; mostrou-se necessária devido à urgência com que a pandemia nos submeteu. Entretanto, "passado o susto" é preciso, enquanto professores e professoras, encontrar caminhos que proporcionem aprendizagens 
significativas no mundo virtual, sem que permaneçamos estagnados em práticas maçantes e retrógradas. Sobretudo, perante os desafios que se apresentam a cada semestre letivo, turmas e/ou disciplina lecionada, possamos fortalecer nossa prática e, se preciso, reinventá-la.

\section{Referências}

ALONSO, Katia Mosorov; SILVA, Danilo Garcia; A educação a distância e a formação on-line: o cenário das pesquisas, metodologias e tendências. Educ. Soc., Campinas, v. 39, n. 143, p.499-514, abr.-jun. 2018. DOI: 10.1590/ES0101-73302018200082.

ALMEIDA, Hélio Mangueira. A didática no Ensino Superior: práticas e desafios. Estação científica, Juiz de Fora, nâ14, jul.-dez, 2015.

BARBOSA, Ana Mae. A imagem no ensino de Arte. Anos 1980 e novos tempos. 8. ed. São Paulo: Perspectiva, 2012.

BRIDI, Maria Aparecida. A pandemia Covid-19: crise e deterioração do mercado de trabalho no Brasil. Estud. av., São Paulo, v. 34, n. 100, p.141-165, dez. 2020.

CADAU, Vera Maria. Reinventar a escola. Petrópolis, RJ: Vozes, 2000.

DOSEA, Giselle Santana et al. Métodos ativos de aprendizagem no ensino online: a opinião de universitários durante a pandemia de COVID-19. V. 10, n.1, 2020. https://doi.org/10.17564/2316-3828.2020v10n1p137-148

FARIA, João Roberto; GUINSBURG, J. História do teatro brasileiro, volume 2: do modernismo às tendências contemporâneas. São Paulo: Perspectiva: Edições SESCSP, 2013.

FIOR, Camila Alves; MERCURI, Elizabeth. Envolvimento acadêmico no ensino superior e características do estudante. Rev. bras. orientac. prof, Florianópolis, v. 19, n. 1, p.85-95, jun. 2018. http://dx.doi.org/1026707/1984-7270/2019v19n1p85.

FREIRE, Paulo. Pedagogia da autonomia: saberes necessários à prática educativa. São Paulo: Paz e Terra, 2006.

GOMES, Sidmar Silveira. Entre arte e pedagogia em tempos de pandemia: ensino remoto e mediação teatral. Revista da FUNDARTE. Montenegro, p.01-20, ano 21, no 44, janeiro/março de 2021.

GUSSO, Hélder Lima et al. Ensino Superior em Tempos de Pandemia: Diretrizes à Gestão Universitária. Educ. Soc., Campinas, v. 41, e238957, 2020. Disponível em: <http://www.scielo.br/scielo.php?script=sci_arttextpid=S0101-

$73302020000100802 \& \operatorname{lng}=e n \& n r m=i s o>$. 
GUTIÉRREZ, Antonio L. García. A ojos de la arena: ejercicios de desclasificación. Editado por ACCI ediciones. Primeira edição. Abril, 2020. ISBN: 978-84-17867-82-9.

LIBÂNEO, José Carlos. Pedagogia e pedagogos, para quê?.2.ed. São Paulo: Cortez, 1999.

LOPES, Hannah. Experiência Cênica e Cultura Digital: Possibilidades Teatrais em Meios Virtuais. Manzuá: Revista de Pesquisa em Artes Cênicas, v. 3, n. 2, p.139-159, 10 jan. 2021

MAGALDI, Sábato. Panorama do Teatro brasileiro. Global: São Paulo, 6 Ed, 2004.

MAIER, Suellen Rodrigues de Oliveira; MATTOS, Magda de. O trabalhar e o estudar no contexto universitário: uma abordagem com trabalhadores-estudantes. Santa Maria, v. 42, n.1, p.179-185, jan./jun. 2016.

MORAES, Martha Lemos de. Formação de espectadores na escola: mediações e desdobramentos estéticos do espetáculo "Axé Nzinga". Urdimento - Revista de Estudos em Artes Cênicas, Florianópolis, v.1, n. 34, p.204-223, mar./abr. 2019.

OLIVEIRA, Raphael; MÉLO, Fernanda. Corpo, Teatro e Isolamento: relatos de um ator em uma experiência cênico-digital. Manzuá: Revista de Pesquisa em Artes Cênicas, v. 3, n. 2, p.46-59, 10 jan. 2021.

PUPO, Maria Lucia de Souza Barros. Mediação artística, uma tessitura em processo. Urdimento - Revista de Estudos em Artes Cênicas, [S. l.], v. 2, n. 17, p.113-121, 2011.

PRANDI, Luiz Roberto. Tendências do processo didático-pedagógico no ensino superior na contemporaneidade. akrópolis Umuarama, v. 17, n. 3, p.137-142, jul./set. 2009.

RIZZI, Maria Christina de Souza Lima. Caminhos metodológicos. In: BARBOSA, Ana Mae. (org.). Inquietações e mudanças no ensino da arte. 3. ed., São Paulo: Cortez, 2007.

RONDINI, Carina Alexandra; PEDRO, Ketilin Mayra. M.; DUARTE, Cláudia dos Santo. Pandemia do covid-19 e o ensino remoto emergencial: mudanças na práxis docente. Interfaces Científicas - Educação, [S. l.], v. 10, n. 1, p.41-57, 2020.

SANTOS, Boaventura de Sousa. A cruel pedagogia do vírus. São Paulo: Boitempo, 2020.

SANTOS, Geórgia Maria Ricardo Félix; SILVA, Maria Elaine; BELMONTE, Bernardo do Rego. COVID-19: emergency remote teaching and university professors' mental health. Revista Brasileira de Saúde Materno Infantil, v. 21, n. 1, 2021.

SEABRA, Filipa; AIRES, Luísa; TEIXEIRA, António. Transição para o ensino remoto de emergência no ensino superior em Portugal - um estudo exploratório. São Paulo: Dialogia, n. 36, p.316-334, set./dez. 2020. https://doi.org/10.5585/dialogia.n36.18545 
SILVA, Rosa Jussara Bonfim. Reflexões acerca do trabalho home office ocasionado pela pandemia da covid-19. Revista humanidades e Tecnologia (FINOM), v.25, n.1, 2020.

TU, Huilan et al. Current epidemiological and clinical features of COVID-19: a global perspective from China. Journal of Infect, Volume 81, Edição 1, julho de 2020 , páginas 1-9. https://doi.org/10.1016/j.jinf.2020.04.011

Recebido em: 12/05/2021

Aprovado em: 26/09/2021 